\title{
SURVEY PERILAKU MASYARAKAT TERHADAP POPULASI TUNGAU DEBU RUMAH DI KELURAHAN TITIWUNGEN SELATAN KECAMATAN SARIO KOTA MANADO
}

\author{
Ihat S.E. Purba \\ Victor D. Pijoh \\ J.Runtuwene
}

\author{
Bagian Parasitologi Fakultas Kedokteran Universitas Sam Ratulangi Manado
}

\begin{abstract}
The term House Dust Mites has been applied to a large number of mites found associated with dust in dwellings. This mites can be found in mattresses, pillows, overstuffed furniture and another place where human rest. House Dust Mites can be a important cause of allergic reaction like asthma, rhinitis, conjunctivitis, and atopic dermatitis. The increase of house dust mites and allergic diseases because some factors such as problems of inadequate treatment of patients, medical officers are less able to correctly diagnose, problems of the physical environment, and different ways of life that may be supported from the socioeconomic individuals. This research are aimed to know the knowledge, atitude, and action of community about House Dust Mites. This research is a descriptive research using survey method. It was conducted in the South Titiwungen Village, Sario Sub-District, Manado with total sample 92 head of family. Based on the result of research method showed that $56,5 \%$ of community have the good knowledge about house dust mites , 98,7\% of community have the good atitude and $89,1 \%$ of community also have the good action.
\end{abstract}

Keywords: behavior, community, house dust mites

\begin{abstract}
Abstrak: Istilah tungau debu rumah telah digunakan untuk menyatakan sejumlah tungau yang ditemukan berasosiasi dengan debu di rumah-rumah tempat tinggal. Tungau ini dapat ditemukan di kasur, bantal, perabot rumah tangga dan di tempat lain dimana manusia beristirahat. Tungau debu rumah merupakan penyebab penting dalam timbulnya penyakit alergi seperti asma, konjungtivitis, rinithis, dan atopik dermatitis. Terjadinya peningkatan tungau debu rumah dan penyakit alergi ini karena beberapa faktor seperti masalah penanganan penderita yang tidak adekuat, petugas medis kurang mampu mendiagnosis dengan tepat, dan juga masalah faktor lingkungan fisik serta perbedaan cara hidup masyarakat yang kemungkinan di tunjang dari sosioekonomi individu. Penelitian ini bertujuan untuk mengetahui pengetahuan, sikap dan tindakan masyarakat terhadap populasi tungau debu rumah. Penelitian ini merupakan jenis penelitian Deskriptif dengan metode survey. Lokasi di Kelurahan Titiwungen Selatan, Kecamatan Sario dengan jumlah sampel sebanyak 92 KK. Penelitian ini menunjukkan bahwa 56,7\% masyarakat memiliki pengetahuan baik, 97,8\% masyrakat memiliki sikap baik dan 89,1\% tindakan masyarakat juga sudah baik.
\end{abstract}

Kata kunci: perilaku, masyarakat, tungau debu rumah

Tungau debu rumah terdapat di seluruh dunia. Ada beberapa spesies tungau debu rumah (TDR), namun terdapat dua spesies yang paling umum ditemukan di seluruh dunia yaitu Dermatophagoides farinae dan Dermatophagoides pteronyssinus. ${ }^{1,2}$ Sedikitnya 50-80 \% dari angka kejadian asma di dunia disenarai tercetus oleh debu rumah.
Di indonesia prevalensi asma belum diketahui secara pasti namun diperkirakan 2-5\% penduduk Indonesia menderita asma. ${ }^{3}$

Beberapa penelitian di Jakarta Pusat, Aulung et al telah memeriksa 5.237 gram debu rumah yang berisi 343 tungau yang terdiri atas 6 genus. Pada penelitian lanjutannya, dilaporkan dari 5.411 gram 
debu rumah 876 tungau yang terdiri atas 7 genus. Pada penelitian Sundaru di Jakarta dari 32,6 gram debu rumah yang berasal dari 20 rumah penderita asma, didapatkan tungau sebayak 1.480 yang terdiri atas 10 genus. ${ }^{4}$

Manan juga telah melakukan pemeriksaan terhadap 156,03 gram debu kasur kapuk dari perumahan BTN Pamulang dan mendapat jumlah TDR rata-rata 147 tungau pergram debu kasur dengan jumlah total tungau 26.470 yang terdiri ata 5 genus yaitu D.pteronyssinus, D.farinae, G.destructor, Suidasia medinesis, Cheiletus eredetus, dan didominasi oleh D.pteronyssinus, serta G.destructor. ${ }^{4}$

Terjadinya peningkatan tungau debu rumah dan penyakit alergi ini karena beberapa faktor seperti masalah penanganan penderita yang tidak adekuat disebabkan oleh masyarakat tidak memahami kondisi penyakit dan pengobatannya karena tidak mendapat pengetahuan yang cukup tentang penyakit alergi, petugas medis kurang mampu mendiagnosis dengan tepat dan kurang mampu melakukan penilaian beratnya penyakit sehingga berakibat pengobatan yang dilakukan penderita kurang memadai, dan juga masalah faktor lingkungan fisik serta perbedaan cara hirup yang kemungkinan di tunjang dari sosioekonomi individu. Karena lingkungan dalam rumah mampu memberikan kontribusi besar terhadap faktor pencetus penyakit alergi, maka perlu adanya perhatian khusus pada beberapa bagian dalam rumah. Perhatian tersebut ditujukan pada keberadaan alergen dan polusi udara yang dapat dipengaruhi oleh faktor kondisi lingkungan rumah dan perilaku masyarakat. $^{5}$ Komponen kondisi lingkungan rumah yang dapat mempengaruhi seperti keberadaan debu, bahan dan desain dari fasilitas perabotan rumah tangga yang digunakan jarang dibersihkan, misalnya karpet, boneka, sofa kain, korden, koran, majalah, buku-buku, kasur, bantal dan guling yang menyebabkan suhu ruangan menjadi panas dan lembab., ${ }^{4,5}$ Tujuan penelitian untuk melakukan penelitian bagaimana perilaku masyarakat terhadap populasi tungau debu rumah di Kelurahan Titiwungen, Kecamatan Sario, Kota Manado.

\section{BAHAN DAN CARA PENELITIAN}

Penelitian ini merupakan jenis penelitian deskriptif dengan metode survey. Populasi dalam penelitian ini adalah seluruh kepala keluarga yaitu 1113 KK yang tinggal di Kelurahan Titiwungen Selatan. Besar sampel yang diambil $92 \mathrm{KK}$. Variabel dalam penelitian ini meliputi umur, jenis kelamin, pendidikan, pekerjaan, pengetahuan, sikap dan tindakan. Metode pengumpulan data menggunakan teknik wawancara dengan menggunakan kuesioner. Data yang diperoleh dianalisis dengan cara Analisis Univariat. Analisis Univariat bertujuan untuk memperoleh gambaran setiap karakteristik masing-masing variabel yang diteliti.

\section{HASIL PENELITIAN}

Untuk mengetahui distribusi penduduk berdasarkan kelompok umur, jenis kelamin, tingkat pendidikan dan jenis pekerjaan dapat dilihat dalam tabel berikut ini.

Tabel 1. Distribusi responden berdasarkan umur

\begin{tabular}{ccc}
\hline Umur & Jumlah & $\mathbf{( \% )}$ \\
\hline $19-24$ & 7 & 7,6 \\
$25-40$ & 19 & 20,7 \\
$41-65$ & 66 & 71,7 \\
Total & 92 & 100 \\
\hline
\end{tabular}

Tabel 1 di atas menunjukkan bahwa responden yang paling banyak berumur 4165 tahun $(71,7 \%)$, dan paling sedikit berumur 19-24 tahun (7,6\%).

Tabel 2. Distribusi responden berdasarkan jenis kelamin

\begin{tabular}{ccc}
\hline Jenis kelamin & Jumlah & $\mathbf{( \% )}$ \\
\hline Laki-laki & 30 & 32,6 \\
Perempuan & 62 & 67,4 \\
Total & 92 & 100 \\
\hline
\end{tabular}


Tabel 2 di atas menunjukkan bahwa responden yang paling banyak adalah perempuan 62 responden $(67,4 \%)$ sedangkan laki-laki sebanyak 30 responden (32,6\%).

Tabel 3. Distribusi responden berdasarkan pendidikan terakhir

\begin{tabular}{ccc}
\hline Pendidikan & Jumlah & $\mathbf{( \% )}$ \\
\hline SD & 16 & 17,4 \\
SMP & 9 & 9,8 \\
SMA & 62 & 67,4 \\
S1 & 5 & 5,4 \\
Total & 92 & 100 \\
\hline
\end{tabular}

Tabel 3 di atas menunjukkan bahwa tingkat pendidikan responden yang terbanyak adalah tamat SMA yaitu sebanyak 62 responden $(67,4)$ dan yang terkecil adalah $\mathrm{S} 1$ yaitu 5 responden (5,4\%).

Tabel 4. Distribusi responden berdasarkan Pekerjaan

\begin{tabular}{lcc}
\hline Pekerjaan & Jumlah & $\mathbf{( \% )}$ \\
\hline Pegawai Negeri & 8 & 8,7 \\
Swasta/Wiraswasta & 28 & 30,4 \\
Buruh & 2 & 2,2 \\
Mahasiswa & 6 & 6,5 \\
Pensiun & 11 & 12,0 \\
IRT & 37 & 40,2 \\
Total & 92 & 100 \\
\hline
\end{tabular}

Tabel 4 di atas menunjukkan bahwa jenis pekerjaan terbesar adalah Ibu Rumah Tangga (IRT), yaitu 37 responden (40,2\%) dan yang terkecil, yaitu buruh sebanyak 2 responden $(2,2 \%)$.

Tabel 5. Distribusi menurut tingkat pengetahuan responden terhadap tungau debu rumah

\begin{tabular}{ccc}
\hline Kategori & Jumlah & $\mathbf{( \% )}$ \\
\hline Baik & 52 & 56,5 \\
Buruk & 40 & 43,5 \\
Total & 92 & 100 \\
\hline
\end{tabular}

Tabel 5 menunjukkan bahwa tingkat pengetahuan terbesar adalah berpengetahuan baik yaitu sebanyak 52 responden (56,5\%) dan terkecil berpengetahuan buruk sebanyak 40 respoden (43,5\%).

Tabel 6. Distribusi menurut sikap responden terhadap tungau debu rumah

\begin{tabular}{ccc}
\hline Kategori & Jumlah & $\mathbf{( \% )}$ \\
\hline Baik & 90 & 97,8 \\
Buruk & 2 & 2,2 \\
Total & 92 & 100 \\
\hline
\end{tabular}

Tabel 6 di atas menunjukkan bahwa sikap responden yang terbesar adalah sikap baik yaitu 90 responden (97,8\%) dan yang terkecil adalah sikap buruk sebesar 2 responden (2,2\%).

Tabel 7. Distribusi menurut tindakan responden terhadap tungau debu rumah

\begin{tabular}{ccc}
\hline Kategori & Jumlah & $\mathbf{( \% )}$ \\
\hline Baik & 82 & 89,1 \\
Buruk & 10 & 10,9 \\
Total & 92 & 100 \\
\hline
\end{tabular}

Tabel 7 di atas menunjukkan bahwa tindakan responden yang terbesar adalah tindakan baik yaitu 82 responden $(89,1 \%)$ dan yang terkecil adalah sikap buruk sebesar 10 responden (10,9\%).

\section{PEMBAHASAN}

\section{Karekteristik responden}

Dari hasil penelitian yang telah dilakukan didapatkan responden yang paling banyak berumur 41-65 tahun (71,7\%). Jenis kelamin responden menunjukkan bahwa responden yang paling banyak adalah perempuan (67,4\%).

Dalam penelitian ini tingkat pendidikan responden menunjukkan bahwa responden yang terbanyak adalah tamat SMA yaitu sebanyak 62 responden $(67,4)$. Menurut 
UU No. 20 Tahun 2003 Tentang Sistem Pendidikan Nasional, Pendidikan adalah usaha sadar dan terencana untuk mewujudkan suasana belajar dan proses pembelajaran agar peserta didik secara aktif mengembangkan potensi dirinya untuk memiliki kekuatan spiritual keagamaan, pengendalian diri, kepribadian, kecerdasan, akhlak mulia, serta keterampilan yang diperlukan dirinya, masyarakat, bangsa dan negara. Untuk itu seseorang perlu memiliki pendidikan. Seperti dikemukakan oleh Notoatmodjo juga bahwa melalui pendidikan seseorang akan belajar dan memperoleh pengetahuan, dimana dalam pendidikan iu terjadi proses perubahan dari tidak tahu menjadi tahu, dari tidak dapat mengerjakan menjadi dapat mengerjakan sesuatu. Pekerjaan responden dalam penelitian ini dikelompokkan menjadi 6 yaitu responden yang bekerja sebagai PNS, Swasta/Wiraswasta, Buruh, Mahasiswa, Pensiun dan IRT (Ibu Rumah Tangga). Hasil yang didapatkan menunjukkan proporsi paling banyak menunujukkan yang IRT sebanyak 40,2\%. Hal ini juga bisa terjadi karena penelitian dilakukan pada pagi hari sehingga sebagian besar masyarakat yang bekerja tidak berada di rumah.

\section{Pengetahuan responden}

Berdasarkan data menunjukkan bahwa pengetahuan responden terhadap tungau debu dikategorikan baik (56.5\%). Hal ini dapat dilihat dari beberapa pertanyaan kuesioner tentang tungau debu rumah yaitu pengetahuan responden bahwa penyakit yang disebabkan oleh tungau debu rumah adalah alergi sebanyak 57,6\% responden yang tahu. Hal ini menunjukkan bahwa masyarakat sudah lebih banyak yang tahu daripada yang tidak tahu dan pentingnya pengetahuan ini yakni sebagai usaha untuk meningkatkan kesehatan agar sedapat mungkin terhindar dari penyakit alergi yang disebabkan oleh tungau debu rumah. Menurut Saleha Sungkar, tungau debu merupakan faktor pencetus timbulnya penyakit alergi. ${ }^{6}$ Pengetahuan responden bahwa resiko penyakit yang disebabkan oleh tungau debu dapat menyebabkan penyakit pada orang yang rentan atau sensitive saja hanya $22,8 \%$ yang tahu dan $77,2 \%$ tidak tahu. Hal ini menunjukkan bahwa masyarakat belum mengetahui bahwa penyakit alergi sangat rentan terhadap orang yang sensitive terhadap debu rumah. Masyarakat Indonesia ratarata tidur 6-8 jam sehari, hal ini berarti dalam sehari selama itu pula mereka berada di kamar tidur dan melakukan kontak dengan kasur sehingga apabila kasur tercemar oleh TDR, maka lebih kurang sepertiga masa hidupnya mereka melakukan kontak dengan TDR. Bagi yang tidak sensitif hal tersebut tidak masalah tetapi bagi orang yang sensitif ini merupakan masalah serius karena dapat menimbulkan reaksi alergi. ${ }^{7}$ Pengetahuan responden bahwa tempat yang banyak ditemukan tungau debu rumah adalah kasur kapuk, seprei, karpet dan sofa sebanyak $60,9 \%$ yang tahu. Ini menunjukkan bahwa masyarakat tahu bahwa tungau debu berada di tempat atau lingkungan yang menghasilkan debu yang banyak. Sebelumnya juga telah dilakukan penelitian yang oleh Kusuma Yudopranoto di komplek perumahan PJKA kelurahan Randusari Semararang yang menyatakan bahwa populasi kasur kapuk lebih banyak daripada non kapuk. ${ }^{7}$ Hal ini sesuai teori yang diungkapkan oleh Saleha Sungkar bahwa tungau debu rumah dapat ditemukan terutama di tempat tidur, sprei, kasur, bantal karpet, lantai. ${ }^{6}$ Kemudian yang tahu bahwa ukuran dari tungau debu rumah adalah sangat kecil (tidak dapat dilihat oleh mata secara langsung) hanya 39,1\%. Menurut Saleha Sungkar, ukuran dari tungau debu adalah 0,2-1,2 mm. Karena ukurannya yang kecil, tungau ini sering tidak terlihat dengan mata manusia. ${ }^{6}$ responden yang tahu bahwa makanan dari tungau debu adalah daki dan serpihan kulit hanya sebesar 12,0\%. Hal ini menunjukkan bahwa responden hanya terbatas pada pengetahuan yang umum saja, sedangkan pengetahuan yang lebih tinggi seperti ukuran dan makanan dari tungau debu tidak 
diketahui dengan baik. Sehingga didapatkan responden lebih banyak yang tidak tahu. Pengetahuan responden bahwa cara pemberantasan tungau debu rumah adalah dengan menjaga kebersihan sebanyak $58,7 \%$ tahu dan pengetahuan responden bahwa yang berperan dalam pemberantasan tungau debu rumah adalah seluruh anggota keluarga 63,0\% yang tahu dan 37,0\% yang tidak tahu. Menurut Saleha sungkar salah satu cara pemberantasan TDR dapat dilakukan dengan cara menjaga kebersihan. ${ }^{6}$

\section{Sikap responden}

Dari penelitian didapatkan bahwa lebih banyak responden yang memiliki sikap baik terhadap kebersihan rumah yang mempengaruhi populasi tungau debu rumah yaitu 90 responden (97,8\%) daripada responden yang memiliki tindakan yang kurang baik hanya 2 responden $(2,2 \%)$. Seluruh masyarakat menyatakan sikap yang positif jika diadakan penyuluhan tungau debu rumah dan pemyakit alergi (100\%). Kurangnya informasi masyarakat tentang tungau debu rumah, bisa menjadi salah satu faktor munculnya penyakit alergi. Dari kegiatan ini diharapkan dapat meningkatkan lagi pengetahuan dan kebersihan rumah yang berdampak pada populasi TDR. Sikap masyarakat terhadap peningkatan kebersihan rumah untuk pemberantasan populasi TDR dan pencegahan penyakit alergi sudah positif. Upaya tersebut dapat dilihat seperti sebagian besar responden setuju segera membawa penderita alergi ke rumah sakit atau ke puskemas terdekat (95,7\%). Bagi responden yang ragu-ragu membawa ke rumah sakit, mereka hanya mencoba mengobati sendiri. Sebagian besar responden juga membersihkan perabot rumah dengan lap basah (88,0\%), meskipun sebagian kecil responden yang masih raguragu dan tidak setuju karena menggunakan kemoceng untuk membersihkan perabot rumah. Upaya yang dilakukan juga dengan meletakkan barang-barang seperti pakaian, buku dan mainan dalam lemari yang tertutup rapat (94,6\%), mengganti seprei dan sarung bantal seminggu sekali (92,4\%), menjemur kasur, bantal dan guling seminggu sekali $(94,6)$, dan selalu membuka jendela rumah agar sinar matahari dapat masuk ke dalam rumah (100\%). Hal ini sesuai Menurut Saleha Sungkar yang mengatakan bahwa untuk menghindari TDR, rumah dibersihkan dari debu dengan cara di sapu dan dipel setiap hari dan perabot rumah dibersihkan dengan lap basah. Jangan membersihkan dengan kemoceng/dikebut karena debu tidak hilang tetapi justru beterbangan.Seprei dan sarung bantal diganti sekurang-kurangnya seminggu sekali sedangkan kasur, bantal dan guling dijemur seminggu sekali, dan mengupayakan agar sinar matahari dapat masuk ke dalam rumah dengan memuka jendela, memasang genteng kaca. ${ }^{6}$

\section{Tindakan responden}

Dari penelitian didapatkan bahwa lebih banyak responden yang memiliki tindakan baik terhadap kebersihan rumah yaitu 82 responden (89,1\%) daripada responden yang memiliki tindakan yang kurang baik hanya 10 responden (10,9\%). Menurut teori Bloom, pengetahuan merupakan pedoman dalam membentuk suatu tindakan seseorang. ${ }^{8}$ Hal ini sesuai dengan hasil penelitian yang didapatkan bahwa pengetahuan responden sebagian besar adalah baik (56,5\%). Jadi tindakan yang dilakukakan oleh masyarakat secara keseluruhan baik karena sudah mencerminkan tindakan untuk pemberantasan tungau debu rumah. Seperti membersihkan lantai rumah setiap hari (100\%), mengepel lantai rumah setiap hari $(34,8 \%)$, membersihkan perabot rumah dengan lap basah $(63,8 \%)$, meletakkan pakaian di lemari tertutup (96,7\%), meletakkan buku-buku di lemari tertutup (47,8), mengganti seprei dan sarung bantal seminggu sekali (59,8\%), menjemur kasur bantal dan guling seminggu sekali $(53,3 \%)$ dan membuka jendela setiap hari agar sinar matahari dapat masuk ke dalam rumah $(94,6)$. Hal ini sesuai dengan teori bahwa pemberantasan tungau debu yaitu dengan cara 
seluruh rumah disapu setiap hari dan dipel, perabot rumah dibersihkan dengan lap basah, hindari meletakkan barang-barang seperti buku, tumpukan kertas, mainan, botol dan lainnya diatas meja kursi dan dipan, karena debu mudah menempel pada barang tersebut, barang-barang disimpan di dalam lemari yang tertutup rapat, mengganti seprei dan sarung seminggu sekali, menjemur kasur bantal seminggu sekali, membuka jendela agar matahari dapat masuk, yang maka dapat mencegah terjadinya penyakit alergi. ${ }^{4,6}$

Maka secara garis besar dapat digambarkan bahwa perngetahuan responden, sikap dan perilaku yang ditunjukkan sudah mencerminkan perilaku yang baik. Meskipun dalam hal ini terdapat keterbatasan penelitian yaitu pengumpulan data dengan kuesioner ini bersifat subjektif sehingga kebenaran data sangat bergantung pada kejujuran responden. Selain itu terdapat pula keterbatasan waktu dan tenaga, sehingga subjek yang diperoleh relatif sedikit.

\section{SIMPULAN}

Berdasarkan hasil penelitian dapat diambil kesimpulan bahwa perilaku masyarakat Kelurahan Titiwungen Selatan adalah baik, yaitu:

1. Masyarakat Kelurahan Titiwungen Selatan memiliki pengetahuan baik tentang tungau debu rumah.

2. Masyarakat Kelurahan Titiwungen Selatan memiliki sikap baik.

3. Masyarakat Kelurahan Titiwungen Selatan memiliki tindakan baik.

\section{SARAN}

1. Bagi masyarakat untuk lebih memperhatikan kebersihan rumah dan lebih aktif mencari informasi mengenai tungau debu rumah dan penyakit alergi.

2. Bagi institusi kesehatan hendaknya mengadakan penyuluhan tentang tungau debu rumah dan penyakit alergi serta pola hidup yang bersih dan sehat.

\section{UCAPAN TERIMA KASIH}

Ucapan terima kasih disampaikan pada dr. Victor D. Pijoh, M.Kes (penguji I), dr. J. Runtuwene (penguji II), dr. Janno Bernadus, M.Biomed (penguji III) dan semua pihak yang baik secara langsung maupun tidak langsung telah menumbuhkan ide atau gagasan dalam pemikiran penulis sehingga dapat menyelesaikan artikel ini.

\section{DAFTAR PUSTAKA}

1. Varment Guard Pest Library. House Dust Mites. 2007 March. Available from URL:

http://www.varmentguard.com/pestlibrary/ HOUSE\%20DUST\%20MITES.pdf diakses 12 september 2012.

2. Jeong KY, Choi SY, Lee JH, Lee IY, Yong TS, Lee JS, et al. Standardization of House Dust Mite Extracts in Korea. AAIR. 2012 April 12. Available from URL: http://e-

aair.org/DOIx.php?id=10.4168/aair.2012.4. 3.e108 diakses 18 September 2012.

3. Oemiati $R$, Sihombing $M$, Qomariah. Faktor-faktor yang berhubungan dengan penyakit asma di Indonesia. Media Litbang Kesehatan. 2010;20:41.

4. Sujudi Y, Wisesa TW. Tungau Debu Rumah dan Perannya Pada Dermatitis Atopik Anak. Dermatologi anak. 2000;27:36-8.

5. Purnomo. Faktor-Faktor Risiko Yang Berpengaruh Terhadap Kejadian Asma Bronkial Pada Anak. Semarang: Universitas Diponegoro, 2008.

6. Sungkar S. Artropoda Penyebab Alergi dan Reaksi Toksik. In:Susanto I, Ismid IS, Sjarifuddin PK, Sungkar S, editors. Buku ajar parasitologi kedokteran. Edisi keempat. Jakarta: Balai Penerbit FKUI; 2008.p.28990.

7. Yudopranoto K. Perbandingan Populasi Tungau Debu Rumah Pada Kasur Kapuk dan Non-Kapuk di Perumahan PJKA Kelurahan Randusari Semarang Selatan Jawa Tengah. Semarang: Universitas Diponegoro, 2006.

8. Maulana HDJ. Promosi Kesehatan. Jakarta: ECG, 2009. Hal.202-3. 